\title{
Sarah Nancy, La Voix féminine et le plaisir de l'écoute en France aux XVII et $\mathrm{XVIII}^{\mathrm{e}}$ siècles
}

\section{Laura Rescia}

\section{(2) OpenEdition}

\section{Journals}

\section{Edizione digitale}

URL: http://journals.openedition.org/studifrancesi/2143

DOI: 10.4000/studifrancesi.2143

ISSN: 2427-5856

\section{Editore}

Rosenberg \& Sellier

\section{Edizione cartacea}

Data di pubblicazione: 1 aprile 2014

Paginazione: 141

ISSN: 0039-2944

\section{Notizia bibliografica digitale}

Laura Rescia, "Sarah Nancy, La Voix féminine et le plaisir de l'écoute en France aux xvII et xvII' ${ }^{e}$ siècles ", Studi Francesi [Online], 172 (LVIII | I) | 2014, online dal 01 avril 2014, consultato il 18 septembre 2020. URL : http://journals.openedition.org/studifrancesi/2143; DOI : https://doi.org/10.4000/studifrancesi. 2143

Questo documento è stato generato automaticamente il 18 settembre 2020.

\section{(c) (i) (9)}

Studi Francesi è distribuita con Licenza Creative Commons Attribuzione - Non commerciale - Non opere derivate 4.0 Internazionale. 


\title{
Sarah Nancy, La Voix féminine et le plaisir de l'écoute en France aux XVII et XVIII ${ }^{\mathrm{e}}$ siècles
}

\author{
Laura Rescia
}

\section{NOTIZIA}

SARAH NANCY, La Voix féminine et le plaisir de l'écoute en France aux XVII et XVIII ${ }^{\mathrm{e}}$ siècles, Paris, Classiques Garnier, 2012, pp. 402.

1 L'A. indaga la nascita della "tragédie en musique" e il suo rapporto con la voce femminile nell'ottica della ricezione, attraverso lo studio degli scritti teorici sul piacere dell'ascolto. Notoriamente, la critica attuale non è unanime nell'interpretare le reazioni alla nascita dell'opera: riprendendo la prospettiva aperta dagli studi di C. Kintzler, integrati con l'apporto critico di H. Merlin-Kajman, questo studio si interroga opportunamente sulla percezione della voce femminile in un'epoca, il Grand Siècle, in cui, per il teatro in musica, non esiste ancora un'evidenza estetica condivisa

2 La parte più consistente dello studio è dedicata al XVII secolo, quando la nascita dell'opera francese viene posta in rapporto con la pratica italiana. Il teatro in musica francese è concepito innanzitutto come spettacolo, rappresentazione per gli occhi e ascolto della poesia. Il ruolo della musica è dunque sospetto: la preminenza del logos non permette un apprezzamento del canto. Il canto femminile è un rischio, un pericolo: a differenza di quella italiana, la scena francese rifiutò i castrati, riservando alle voci femminili soltanto ruoli secondari; non vennero mai sfruttati i toni alti, né i falsetti. Ma l'assunto di base dei gender studies, che identificano nella repressione del femminile la chiave di volta per spiegare questi fenomeni, viene qui rimesso in discussione. Secondo l'A. il classicismo puntò alla ricerca del piacere nella voce, un piacere derivante dalla semplicità, dalla ricerca della giusta proporzione. La musica è accusata non tanto di causare un piacere colpevole, quanto di ostacolare il piacere della parola. E nel 
contrasto tra phoné e logos, la voce femminile è percepita quale emblema del corpo sessuato, di quell'engouement che avrebbe potuto allontanare il prestigio della parola. L'A. studia, con precisione e sulla base di un'ottima bibliografia primaria, la polemica contro l'opera nel xvil secolo: le filles de l'opéra sono più esposte allo stigma di immoralità, ma non tanto in funzione della loro appartenenza di genere, quanto al fatto che la propensione all'eccesso di ornatus, propria del bel canto italiano, viene percepita come ostacolo al piacere dell'ascolto. La voce cantata è sottoposta agli stessi criteri di giudizio della voce teatrale e di quella eloquente; è l'eccesso ad essere condannato, quello che, nelle parole dei trattatisti dell'epoca, trasforma i volti delle attrici-cantanti in maschere grimaçantes, e fa paragonare i personaggi femminili alle gatte in calore.

Mettendo in parallelo la teorizzazione francese con quella italiana, l'A studia inoltre la percezione del rapporto tra corpo e voce cantata. I trattatisti teorici francesi, a differenza degli omologhi d'oltralpe, non sembrano orientati a studiare il rapporto tra canto e respiro: il suono della voce non è tanto indagato su un piano tecnico, bensì posto in relazione al suo legame con le passioni. Il piacere dell'opera è sempre, nel Grand Siècle, legato alla rappresentazione, alla teatralità più che ai fatti acustici: e la distanza - quell'éloignement che T. Pavel ha tanto esemplarmente collegato all'estetica classica - domina la ricezione. Il piacere di dire, di analizzare e di comprendere non è scindibile dal piacere sensoriale: la necessità di utilizzare la lingua nazionale è funzionale tanto alla politica culturale di Louis XIV quanto alla sensibilità del pubblico, che comincia, come sottolineato negli studi di Merlin-Kajman, a percepirsi come corpo collettivo e soggetto politico. Una parte di minore estensione del saggio è dedicata alla svolta paradigmatica operata nel secolo xviII, quando si afferma la priorità della musica sulla parola, e l'armonia musicale viene messa in rapporto al concetto di verità: il principio del femminile ne viene conseguentemente rivalutato, sulla base della convinzione che la natura esprimerebbe meglio nel canto femminile tutte le variabili emozionali. La donna comincia ad apparire come la migliore interprete della voce delle origini e della sensibilità: un ideale estetico propugnato, come noto, dalla teorizzazione rousseauviana.

Ben documentato, innovativo ma solidamente ancorato nel panorama critico non solo recente, il saggio si avvale sicuramente delle competenze musicali della sua autrice, che offre ai suoi lettori la possibilità di ascoltare, grazie ad un cd allegato al testo, la sua interpretazione di arie sei e settecentesche, con accompagnamento di strumenti d'epoca, in un inedito musicale di grande godibilità. La dimensione interdisciplinare, per una volta, non nuoce alla scientificità della tesi. 